\title{
Fatigue behaviour of laser repairing welded joints
}

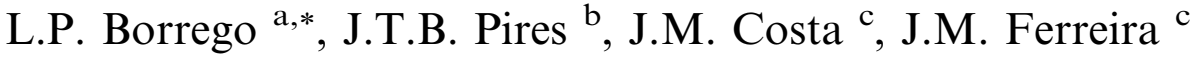 \\ a Department of Mechanical Engineering, Instituto Superior de Engenharia de Coimbra, IPC, Rua Pedro Nunes, \\ Quinta da Nora, 3030-199 Coimbra, Portugal \\ ${ }^{\mathrm{b}}$ Department of Industrial Engineering, Escola Superior de Tecnologia, IPCB Avenida do Empresário, 6000-767 Castelo Branco, Portugal \\ ${ }^{\mathrm{c}}$ Department of Mechanical Engineering, University of Coimbra, Polo II, Pinhal de Marrocos, 3030-201 Coimbra, Portugal
}

Received 16 October 2006; accepted 30 November 2006

Available online 16 February 2007

\begin{abstract}
This paper presents a fatigue study in Nd-YAG laser surface repairing welded joints in specimens of two base materials used in mould production. The tests were carried out in a servo-hydraulic machine in tension, under constant amplitude loading, with two stress ratios $R=0$ and $R=0.4$. Welded specimens were prepared with $\mathrm{U}$ notches and filled with laser welding deposits. The fatigue results are presented in the form of $\mathrm{S}-\mathrm{N}$ curves obtained in welded and non-welded conditions. Complementary measurements of hardness and residual stresses profiles were carried out along the surface of laser welded specimens to understand the observed fatigue behaviour. The melted material was the weaker region, with lower values of hardness and higher tensile residual stresses, presenting also a high number of defects that are potential failure sites. The presence of such defects can explain the relatively poor fatigue strength of the laser repairing joints in comparison to base materials.
\end{abstract}

(c) 2006 Elsevier Ltd. All rights reserved.

Keywords: Mould producing; Laser repairing; Welded joints; Fatigue

\section{Introduction}

Mould producing is one of the more relevant Portuguese industries using high CAD/CAM technologies. The shape and manufacturing of tools for moulds are usually extremely exact and consequently very expensive. Therefore, during moulds manufacturing, the correction of localized imperfections due to design or execution as well as tool marks is very frequent.

In injection and bow moulds for plastic products and in die casting processes of aluminium and magnesium alloys, these tools are subjected to strong thermo-mechanical loads, especially in the case of the aluminium die castings. Moreover, generally thermo-mechanical loading results in damage of the moulds surface in the form of wear or fatigue cracks.

\footnotetext{
* Corresponding author. Tel.: +351 962560101; fax: +351 239790331.

E-mail address: borrego@isec.pt (L.P. Borrego).
} 
Laser-deposit welding, by using modern Nd-YAG lasers, is a new repair process, very flexible, that has the advantage relatively to the traditional methods (micro-plasma and TIG methods) of achieving less change of the metal composition around the repair zone. Moreover, it permits a very accurate deposition of a small volume of filler material at the area chosen in the work-piece surface, without distortion, even in the case of a small thickness of $0.2 \mathrm{~mm}$. Taking in account the costs involved to produce a new mould, is obvious the relevance of the possibility in repairing moulds without significant loss of quality. Therefore, if the operation life of dies could be successfully extended by a regular maintenance of die parts, the final price of moulds will be significantly improved.

Laser cladding or alloying by blowing a powder of a suitable chemical composition and grain size is an alternative welding process by using modern compact diode lasers. Albright [1] stated that by laser cladding or alloying process, a very favourable variation of residual stresses in the thin laser-surfaced layer and the heat-affected zone was obtained whereas the thermal distortion of the part was negligible.

An important property for repairing mould steels is a good weldability in both states prior and after the post-weld heat treatment. Gehricke [2] report the superiority of the maraging steels over the hot-working tool steels. Grum and Slabe also observed $[3,4]$ that the heat treatment of maraging steels including solution annealing and precipitation annealing is less difficult than the heat treatment of hot-working tool steels. Despite these advantages of the maraging steels, the majority of the moulds produced in Portugal for die casting processes of aluminium and magnesium alloys use hot-working tool steels (X $40 \mathrm{CrMoV} 51$ and 40 CrMnNiMo 8 64). For these steels there are no research studies about the laser-deposit welding process effects in respect to microstructure, hardness and residual stresses variations in the laser-deposited layer and in the heat-affected zone. These variations will have an important influence in the thermal-mechanical fatigue strength of the moulds parts.

In this study, a fatigue analysis of moulds steels with surface defects repaired by the laser process was performed. An Nd-YAG laser process was used in order to simulate the repair of damaged tool surfaces. Fatigue tests were carried out with plain specimens as well as with surface welded specimens. Microhardness analyses of the laser welded regions will also be performed after laser repair. Finally, an analysis of the residual stresses distribution will be carried out.

\section{Experimental details}

In this study, two base materials were used, namely hot-working tool steels X $40 \mathrm{CrMoV} 51$ and 40 CrMnNiMo 864 . Both alloy steels were investigated in the as received condition with quenching and tempering. The chemical composition and the mechanical properties of these alloys are shown in Tables 1 and 2, respectively. The X $40 \mathrm{CrMoV} 51$ steel (AISI H13 steel) is mainly used in the production of moulds for die casting processes of aluminium and magnesium alloys and the 40 CrMnNiMo 864 steel (AISI P20 steel) in the production of moulds for injection and bow of plastic products.

Fatigue tests were performed with rectangular cross-section plain specimens as well as with surface welded specimens. Smooth specimens were prepared from base material mould steels, while welded specimens were prepared with $U$ notches and filled with laser welding deposits in order to simulate the repair of damaged tool surfaces. Fig. 1 illustrates the major dimensions of the samples used in the tests. The radius of the U notch was $1 \mathrm{~mm}$ and $0.75 \mathrm{~mm}$ for welded specimens of H13 and P20 mould steels, respectively. Several laser-deposited layers were performed in these specimens.

Welding was conduced with an Nd-YAG laser system, HTS 180 Laser Tool, using a pulsating electric current with $6 \mathrm{~Hz}$ and $8 \mathrm{~ms}$ of impulse time. A filler wire with $0.5 \mathrm{~mm}$ diameter was used. An Ar/He-mixture

Table 1

Chemical composition of the analysed mould steels (wt \%)

\begin{tabular}{lllllllll}
\hline Mould steel & & & $\mathrm{C}$ & $\mathrm{Si}$ & $\mathrm{Mn}$ & $\mathrm{Cr}$ & $\mathrm{Mo}$ & $\mathrm{Ni}$ \\
\hline DIN & AISI & & & & & & \\
\hline X 40 CrMoV 5 1 & H13 & 0.39 & 1.0 & 0.4 & 5.2 & 1.3 & - \\
40 CrMnNiMo 8 64 & P20 & 0.37 & 0.3 & 1.4 & 2.0 & 0.2 & 1.0 \\
\hline
\end{tabular}


Table 2

Mechanical properties of the mould steels

\begin{tabular}{lllll}
\hline Mould steel & & $\sigma_{\mathrm{UTS}}(\mathrm{MPa})$ & $\sigma_{\mathrm{YS}}(\mathrm{MPa})$ & $\varepsilon_{\mathrm{r}}(\%)$ \\
\hline DIN & AISI & & & \\
\hline X 40 CrMoV 5 1 & H13 & 1990 & 1650 & 9 \\
40 CrMnNiMo 8 6 4 & P20 & 995 & 830 & 12 \\
\hline
\end{tabular}

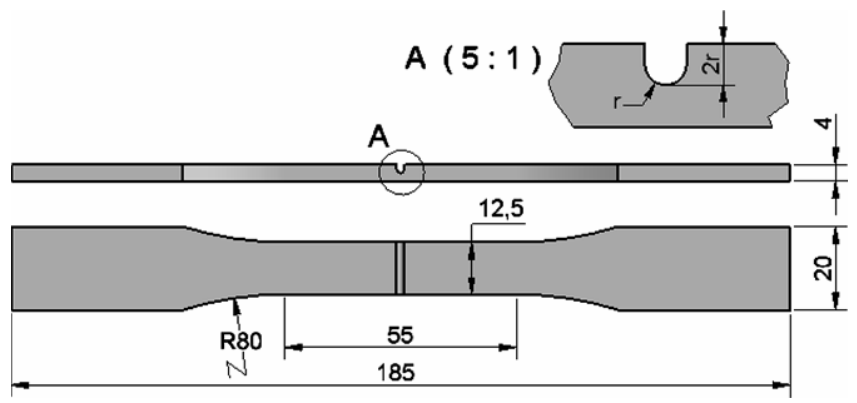

Fig. 1. Geometry of the rectangular cross-section specimens used in the tests (dimensions in $\mathrm{mm}$ ).

$(5 \% \mathrm{He})$ with a flow of $0.6 \mathrm{l} / \mathrm{min}$ was used as shielding gas. The filler material used for the $\mathrm{H} 13$ steel specimens was a stainless steel and for the P20 steel specimens an alloy steel. The chemical composition of the filler materials are presented in Table 3.

All the fatigue tests were performed in load control using a computer-controlled servo-hydraulic Instron machine with $100 \mathrm{kN}$ capacity. The tests were carried out under constant amplitude loading, with two stress ratio $R=0$ and $R=0.4$. All tests were conducted in air, at room temperature and with a load frequency of $25 \mathrm{~Hz}$. The specimens were clamped by hydraulic grips.

In order to characterize the welded joint and the heated affected zone (HAZ) Vickers hardness profiles were obtained using a Struers Type Duramin-1 microhardness tester, with an indentation load of $2000 \mathrm{gf}$ during $15 \mathrm{~s}$, according to the ASTM E 348 standard [5]. The hardness profiles were obtained at the surface, along the direction normal to the laser-deposited material, close to the longitudinal center line of welded specimens. The measurements were performed at each $0.25 \mathrm{~mm}$, along $5 \mathrm{~mm}$ from both sides of the laser weld centre.

The residual stresses were determined at the surface of the specimens by X-ray measurement with a $\Psi$ diffractometer. Interference line profiles of Iron phase $\alpha\{211\}$ planes for the parent materials, and of Iron phase $\gamma\{220\}$ planes for the laser-deposit layer, were mapped using $\mathrm{Cr} \mathrm{K} \alpha$ radiation under different tilt angles $(\psi)$. A wave length in the range 2.289 and $2.29 \AA$ and a Vanadium filter at the diffracted beam were used. After determining the line peaks $2 \Theta \varphi, \psi$ the macroscopic residual stress was calculated by the $\sin ^{2} \psi$ method. The residual stresses were obtained along the direction normal to the laser-deposited material of welded specimens, at exactly the longitudinal center line of specimens. The measurements were performed at the middle of the weld joint, in the parent material at $5 \mathrm{~mm}$ from both sides of the laser weld center and also at the interface between the laser weld and parent material.

Finally, SEM observations of the fatigue fracture surfaces and also of non tested specimens were performed in surface laser welded specimens using a Philips XL30 scanning electron microscope.

Table 3

Chemical composition of the filler materials (wt \%)

\begin{tabular}{llllllll}
\hline Mould steel & $\mathrm{C}$ & $\mathrm{Si}$ & $\mathrm{Mn}$ & $\mathrm{Cr}$ & $\mathrm{Mo}$ & $\mathrm{Ni}$ \\
\hline H13 & 0.15 & 1.5 & 2 & 20 & - & 7 & Rest \\
P20 & 0.35 & 0.3 & 1.2 & 7 & 2 & - & Rest \\
\hline
\end{tabular}




\section{Results and discussion}

Fatigue strength of welded and non-welded specimens are plotted in Fig. 2 for P20 mould steel as nominal stress amplitude, $\Delta \sigma / 2$, against the number of cycles to failure, $N_{\mathrm{f}}(\mathrm{S}-\mathrm{N}$ Wholler curves).

For the non-welded specimens the results were obtained from tests performed at stress ratios $R=0$ and $R=0.4$, while for the welded specimens the results are only for $R=0$. This figure shows an important decrease of the fatigue strength obtained at $R=0.4$ in comparison to the stress ratio $R=0$, i.e., there is a high mean stress effect in the fatigue strength of P20 steel specimens in the range of fatigues lives analysed, which is the typical behaviour generally observed. Welded specimens, tested at $R=0$, present a significant lower fatigue resistance than the correspondent non-welded specimens tested for the same stress ratio. The welded specimen have a plane surface laser welding, therefore there is no stress concentration in the weld joint. Also, the finishing of both welded and non-welded specimens is similar. Therefore, the decrease of the fatigue strength observed in the welded specimens must be due to other factors such as filler material mechanical properties, hardness, residual stresses or welding defects.

The slope of the $\mathrm{S}-\mathrm{N}$ curve, which numerically corresponds to $-\mathrm{m}^{-1}$, is an effective indication of the fatigue initiation period importance [6]. A more inclined slope of the S-N curve indicates a lower contribution of the initiation phase to the total fatigue life. Thus, the higher slope observed in the welded specimens is the reflex of an early crack initiation due, for example, to the presence of welding defects. Fig. 2 shows an increase of the slope from -0.088 to -0.11 between the non-welded and welded specimens tested for $R=0$.

The fatigue results obtained for H13 mould steel at $R=0$ for both welded and non-welded conditions are depicted in Fig. 3. The nominal stress amplitude $\Delta \sigma / 2$ is plotted against the number of cycles to failure $N_{\mathrm{f}}$. As for the P20 steel the results obtained in the H13 hot-working steel show a significant fatigue strength decrease of welded specimens when compared with non-welded specimens. In this material, the slope of the welded specimens $\mathrm{S}-\mathrm{N}$ curve is -0.16 , much greater than the slope of -0.076 observed for the non-welded specimens curve.

Fig. 4 presents the typical Vickers hardness profiles of laser welded specimens, along the transverse direction relatively to laser-deposited material and symmetrically to the weld joint.

From H13 steel hardness profile it can be concluded that the filler material has a significant lower hardness than the parent material and that the thermal effects of the welding laser process induce a slight material hardening in the HAZ and that this zone is very narrow. A near narrow heat-affected zone with less than $0.1 \mathrm{~mm}$ of extension, having approximately constant wide along its contour, was typically observed. A minimum of

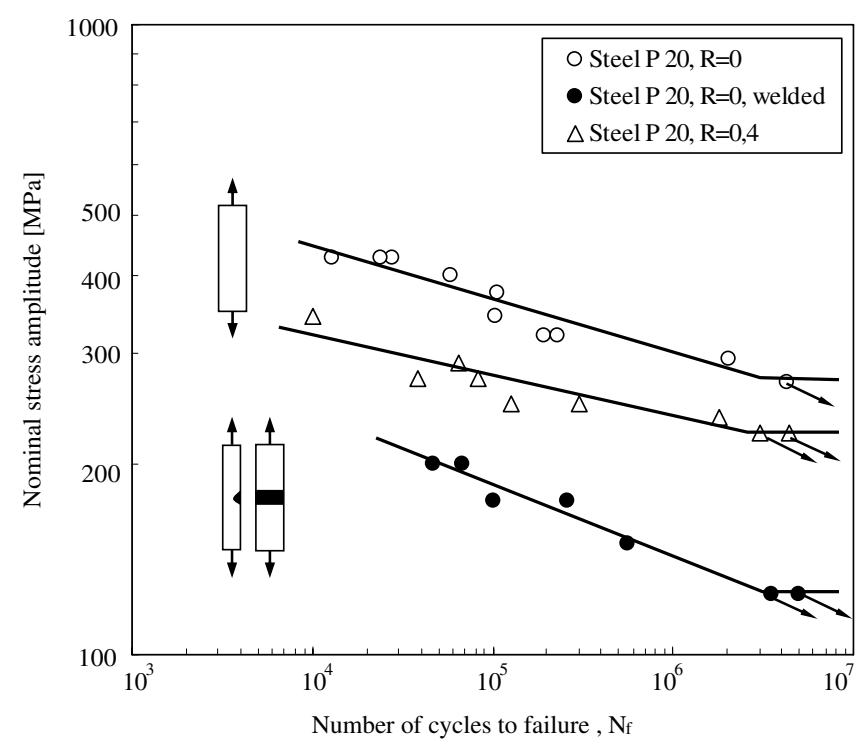

Fig. 2. Nominal stress amplitude versus number of cycles to failure. P20 mould steel. 


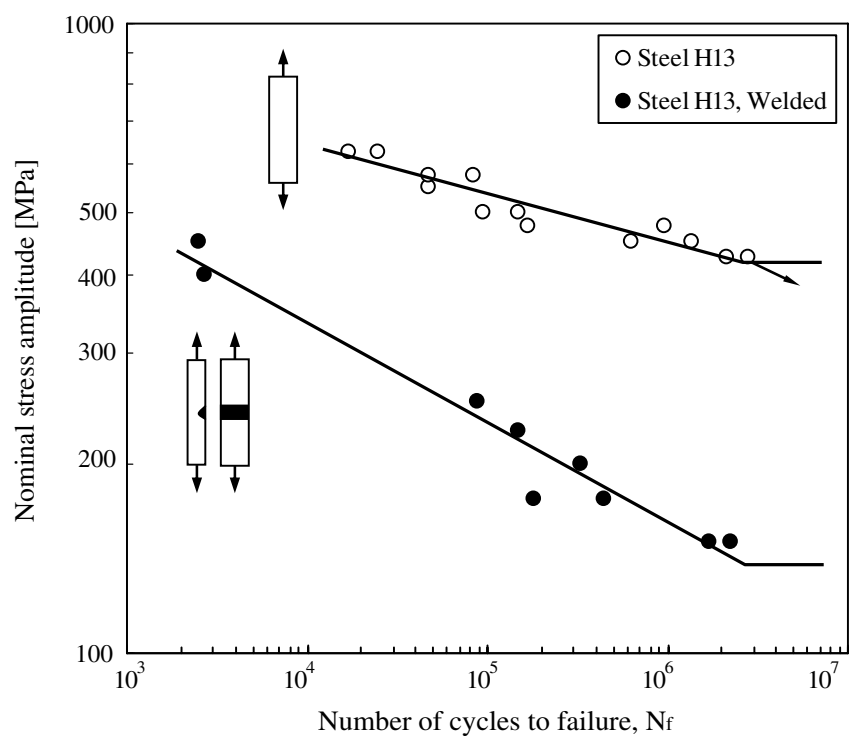

Fig. 3. Nominal stress amplitude versus number of cycles to failure. H13 mould steel. $R=0$.

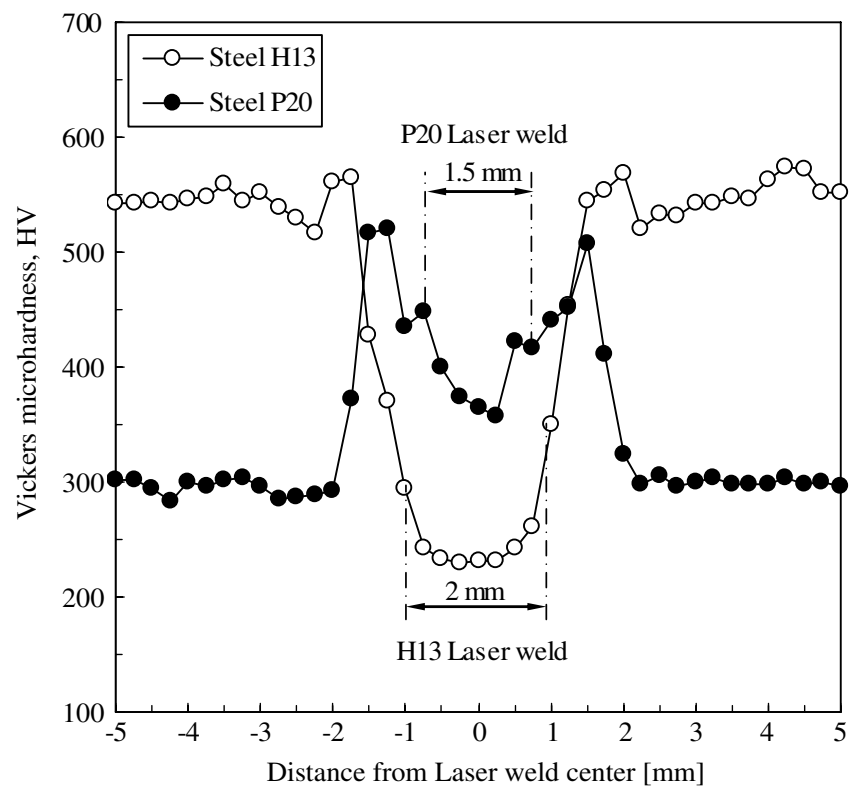

Fig. 4. Hardness profiles in laser welds. H13 and P20 mould steels.

$230 \mathrm{HV}$ was obtained near the middle of the weld joint and a maximum of $670 \mathrm{HV}$ in the HAZ. The P20 steel hardness profile has a different aspect mainly because the filler material used in these laser welded specimens has higher hardness in comparison to the parent material. The heat-affected zone has a slightly higher extension than for the H13 laser welded specimens, with a maximum of $520 \mathrm{HV}$ and the filler metal has a minimum of $350 \mathrm{HV}$ at the middle of the weld joint. This figure shows that the P20 steel filler metal presents higher hardness values than the filler material used in the H13 steel laser welded specimens.

Fig. 5 shows the residual stresses values measured at the surface of the H13 hot-working steel specimens at several points symmetrically to the weld joint. The specimens presented some distortion resulting from the welding process, therefore the residual stresses were determined at both non-aligned and aligned specimen 


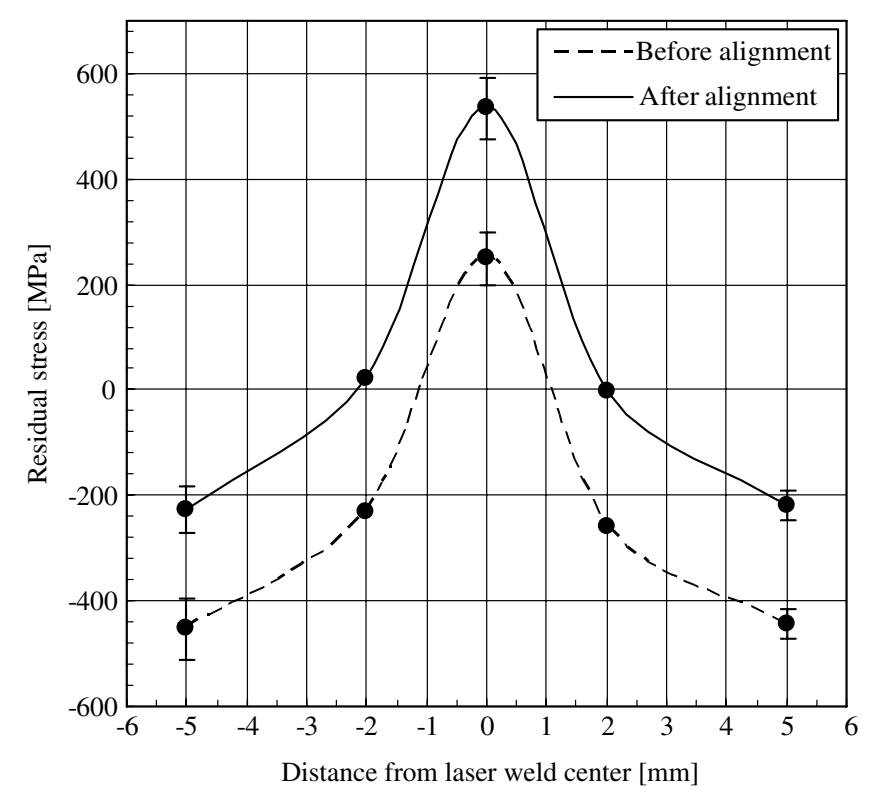

Fig. 5. Residual stresses at laser welds before fatigue testing. H13 mould steel.

conditions. The evaluation of the residual stresses in the aligned condition is important because it corresponds to the real condition of testing of the fatigue specimens. It can be observe that tensile residual stresses at the laser weld centre, and compressive residual stresses at the base material and at the interface. The alignment of the specimen creates additional tensile stresses at the laser-deposit material and reduces the compressive stresses at the other points. The residual stresses observed at critical points (laser-deposited material) increases the mean stress of the fatigue cycle which has a detrimental effect in fatigue lives and contributes as a consequence to the lower fatigue resistance observed in the welded specimens.

Figs. 6 and 7 show some typical features of the fatigue fracture surfaces of P20 and H13 mould steels, respectively.

In both figures many planar defects can be clearly seen in the direction normal to the fracture surface. These defects provide new surfaces were the crack can be more easily initiated due to the lower constraint of the plastic deformation that characterizes the surface grains of a material. The surface finishing of these defects show

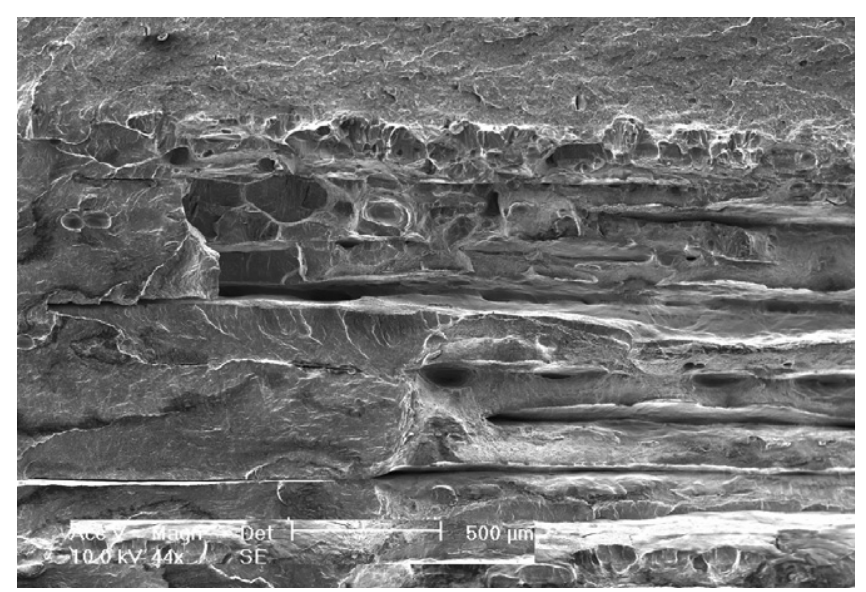

Fig. 6. Fatigue fracture appearance of the H13 mould steel welded specimens. $\Delta \sigma / 2=175 \mathrm{MPa}, R=0$ and $N_{\mathrm{f}}=445.000$ cycles. 

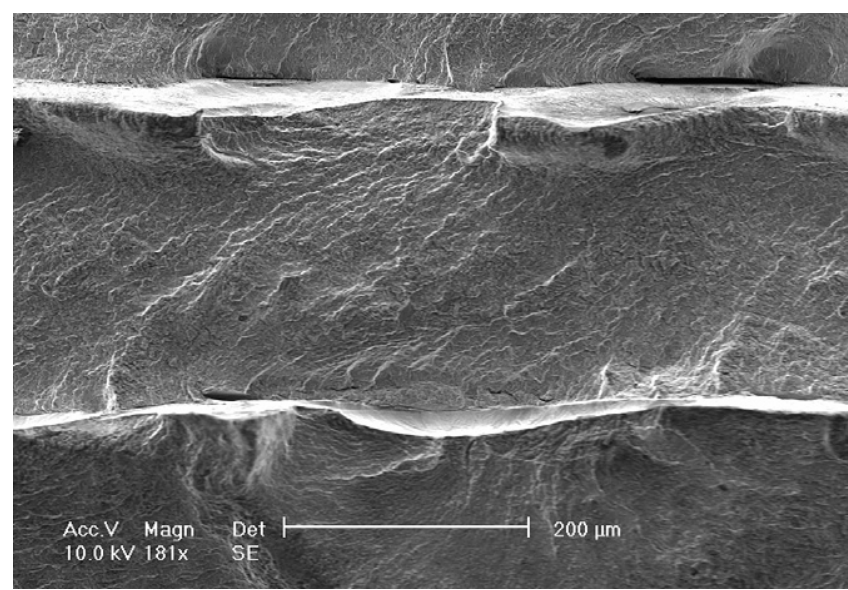

Fig. 7. Fatigue fracture appearance of the $\mathrm{P} 20$ mould steel welded specimens. $\Delta \sigma / 2=175 \mathrm{MPa}, R=0$ and $\mathrm{Nr}=263.0000 \mathrm{cycles}$.

clearly higher roughness than the specimen surface, which also contributes to facilitate crack initiation. Both figures present multiple initiation sites were most of them begin from the surface of the planar defects. Some pores can also be seen, but probably the cracks were not initiated from them, because there are other defects with higher severity where the crack initiation is enhanced.
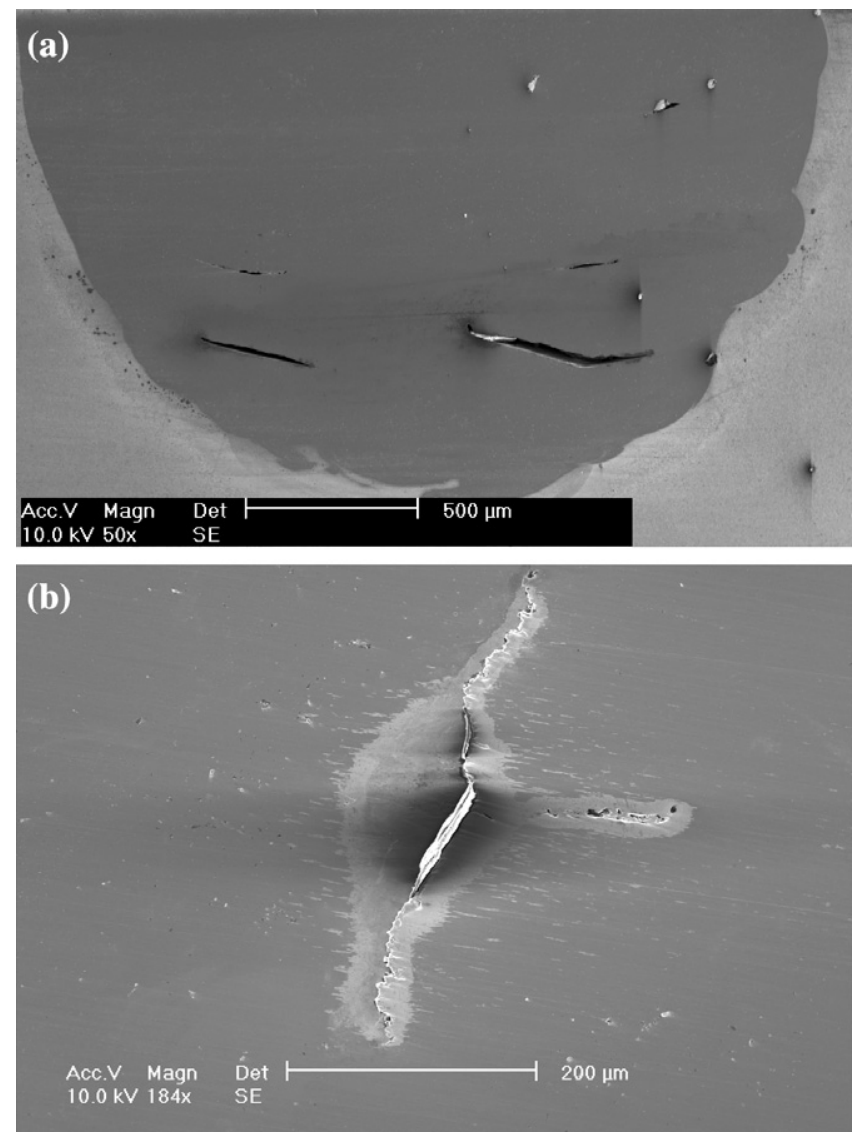

Fig. 8. Defects in the laser-deposited material: (a) SEM image of the repairing joint cross- section; (b) SEM image on a parallel plain to the specimen surface. 
Fig. 8a shows a SEM image of a cross-section of the repairing joint obtained by cutting a H13 welded specimen not used in the fatigue tests. Several large plane defects can be observed that result from a lack of fusion between the successive laser-deposit layers. Although these defects are in a direction almost parallel to the tensile stresses applied to the specimen, they must have a significant effect promoting fatigue crack initiation, and, thus, reducing significantly the total fatigue lives. This also explains the higher slopes observed for the welded specimens (see Figs. 3 and 4) when compared with the slopes of the non-welded specimen curves, as referred before.

Fig. 8b presents also a SEM image of the laser repairing joint, but now on a parallel plane to the specimen surface, obtained by successive rectifications of the specimen surface ( $0.4 \mathrm{~mm}$ from surface). This figure shows a defect that resulted from the cut of the planar defects depicted before in Fig. 8a. The bigger or smaller dimension of the view of this defect depends on if the defect is more or less inclined relatively to the specimen surface.

\section{Conclusions}

The Fatigue strength of H13 and P20 mould steels was obtained in terms of S-N curves, for both non-welding and surface laser welded specimens. Steel P20 presents a lower fatigue resistance in comparison to H13 steel. A significant mean stress effect was observed in P20 mould steel. Repaired joints using Nd-YAG laser welds are significantly weaker than base materials as consequence of lower hardness and higher residual stresses obtained in the laser-deposited material, but also by the high number of defects observed in the filler material, which promote crack initiation, and, therefore are potential failure sites.

\section{Acknowledgements}

The authors acknowledge POCI programme, Project POCI/EME/55918/2004, for funding the work reported and Anibal H. Abrantes S.A. company for providing the specimens and for performing the laser welds.

\section{References}

[1] Albright CE. Laser surface modifications. In: Charschan SS, editor. Guide to laser materials processing. Boca Raton: CRC Press/Laser Institute of America; 1993. p. 97-113 [chapter 6].

[2] Gehricke B. Development, properties and characteristics of a new maraging steel for die casting dies. In: Proceeding of the conference on the die casting technology in harmony with the environment, USA. Cleveland; 1993. p. 209-17.

[3] Grum J, Slabe JM. Possibility of introducing laser surfacing into maintenance service of die-casting dies. Surf Coat Technol 2004;180 181:596-602.

[4] Grum J, Slabe JM. A comparison of toll-repair methods using $\mathrm{CO}_{2}$ laser surfacing and arc surfacing. Appl Surf Sci 2003;208209:424-31.

[5] American Society for Testing and Materials. Standard test method for microhardness of materials. Annual Book of ASTM Standards 2000: vol. 03.01, ASTM E 384.

[6] Lawrence FV, Dimitrakis SD, Munse WH. Factors influencing weldment fatigue. Fatigue and fracture. Handbook american society for metals; 1996. 